DOI 10.37882/2223-2982.2021.12-2.33

\title{
РЕЛИГИОЗНАЯ МКК В УСЛОВИЯХ КОНФЕССИОНАЛЬНЫХ И ЯЗЫКОВЫХ РАЗЛИЧИЙ - ПРОБЛЕМА ИДЕНТИФИКАЦИИ ОБЪЕКТА (НА ПРИМЕРЕ ПЕРЕВОДА ПРАВОСЛАВНЫХ АГИОНИМОВ)
}

\section{OBJECT IDENTIFICATION BARRIER IN RELIGIOUS INTERCULTURAL COMMUNICATION WITH \\ CONFESSIONALLY DIFFERENT \\ PARTICIPANTS: TRANSLATING ORTHODOX AGYONYMS}

S. Ponomareva U. Shavrina

Summary: The article deals with the issues of intercultural religious discourse on the material of the English and Russian languages. The research material was informational messages posted on the website of the Department for External Church Relations of the Russian Orthodox Church. The subject of the research is the methods of translating proper names. Of interest are hagioanthroponyms as a special case of hagionyms, from the point of view of their identification function in the process of intercultural interaction in English. In the context of interfaith and linguistic differences, inaccuracies in the transmission of hagioanthroponyms can serve as an obstacle to successful communication. Also, a certain communicative barrier is the variability in the nomination of the same persons (saints, clergy, etc.).

Keywords: intercultural religious discourse, proper noun, agyonym, agyoanthroponyms, identification function, nomination variability.
$\Pi$ осле периода вынужденной изоляции в советские годы Русская Православная Церковь (РПЦ) осознает потребность активного международного освещения своей деятельности. В настоящее время важным средством распространения православной культуры являются Интернет-ресурсы. К ним относятся официальные церковные сайты, православные средства массовой информации (порталы, Интернет-журналы, новостные сайты и др.); сайты, посвященные церковно-общественной жизни (фонды, форумы, паломнические службы и др.); просветительские сайты о науке, культуре, искусстве и образовании, а также православные Интернетбиблиотеки. В целях просветительской деятельности активно используется официальный сайт Отдела внешних церковных связей Московского Патриархата (ОВЦС). Согласно информации на сайте ОВЦС, это учреждение было образовано «Священным Синодом Русской Пра-
Пономарева Светлана Николаевна

к.филол.н., доцент, Московский государственный университет имени М.В. Ломоносова

spatz@mail.ru

Шаврина Ульяна Андреевна

младший копирайтер, Финтех-компания Револют, ulyana.shavrina@gmail.com

Аннотация: В статье рассматриваются вопросы межкультурного религи0зного дискурса на материале английского и русского языков. Материалом исследования послужили информационные сообщения, размещенные на сайте Отдела внешних церковных связей (ОВЦС) РПЦ. Предметом исследования являются приемы перевода имен собственных. Интерес представляют агиоантропонимы как частный случая агионимов, с точки зрения их идентификационной функции в процессе межкультурного взаимодействия на английском языке. В условиях межконфессиональных и языковых различий неточности передачи агиоантропонимов могут служить препятствием для успешной коммуникации. Так же определенным коммуникативным барьером является и вариативность номинации одних и тех же лиц (святых, священнослужителей и т.п.).

Ключевые слова: англоязычный межкультурный религиозный дискурс, имя собственное, агионим, агиоантропоним, идентификационная функция. вославной Церкви 4 апреля 1946 года, когда развитие внешней деятельности Русской Православной Церкви настойчиво потребовало создания специального церковного органа, который мог бы обеспечить стабильную организацию этой немаловажной стороны церковной жизни» [8].

Перевод русскоязычных православных сайтов, и сайта ОВЦС в особенности, на английский язык, несомненно, способствует распространению православных ценностей за пределами России. Одной из главных переводческих проблем при этом является передача лексики православной сферы. Трудность обусловлена тем, что православная лексика несет культурную информацию, которая должна быть максимально точно передана в тексте перевода, чтобы сформировать у читателя полноценное представление об описываемых предметах и явлениях. 
Особое место в составе православной лексики занимают имена собственные (ИС), связанные со святостью, которые мы вслед за И.В. Бугаевой называем агионимами. Эти языковые единицы требуют крайне внимательного отношения со стороны переводчика. Во-первых, в изначальной языковой среде агионимы, как и другие ИС, «обладают сложной смысловой структурой, уникальными особенностями формы и этимологии, способностями к видоизменению и словообразованию, многочисленными связями с другими единицами и категориями языка» [4]. При переводе значительная часть этих свойств теряется, и, если не принимать это обстоятельство во внимание, переводчик рискует затруднить идентификацию называемого объекта или явления. Во-вторых, агионимы содержат культурную информацию религиозного характера, что, безусловно, требует от переводчика учета не только межкультурного, но и межконфессионального контекста, с тем чтобы точно отразить особенности русского православия и не допустить подмены православных реалий понятиями других христианских конфессий или даже отдельных религий.

Культурное своеобразие народа формируется в результате взаимодействия трех факторов: конфессионально-вероисповедной принадлежности, языка и этничности. Религиозные представления людей накладывают отпечаток на их уклад жизни и мировоззрение и, как следствие, получали отражение в языке. Таким образом идет процесс формирования пласта религиозной лексики, который продолжается и в настоящее время. Религионимы как слова с религиозной семантикой входят в состав культуронимов и называют элементы культуры из сферы религии. В современной лингвистике не существует единой трактовки понятия «религиозная лексика». Мы будем придерживаться дефиниции термина, данной А.А. Азаровым [1], который в Русско-английский словарь религиозной лексики включает терминологию по основным религиям мира. В словарь входит лексика, используемая при отправлении религиозных обрядов, а также в работах по архитектуре культовых сооружений, иконописи, прикладному искусству, истории религии. В словаре приводятся библейские понятия и персонажи, ряд церковно-славянских слов, имена святых, богословов и известных религиозных деятелей. Понятие религиозной лексики трактуется максимально широко и включает лексические единицы, появившиеся в связи с оформлением основных религий мира.

Как отмечает К.А. Тимофеев, религиозная лексика может быть классифицирована по следующим группам:

1. общерелигиозную лексику, к которой относятся понятия, свойственные всем монотеистическим религиям (Бог, праведность и др.);

2. слова, обозначающие понятия, свойственные всем основным христианским конфессиям (Святая Троича, Спаситель и др.);
3. слова, свойственные отдельным христианским конфессиям (наименования священнослужителей: батюшка, пастор; богослужений: обедня, утреня; частей храма: иконостас, паперть и др.) [12].

Общехристианская лексика является универсальной для всех разновидностей христианства. Последняя же группа, это так называемые идионимы (по терминологии В.В. Кабакчи), культурно маркированные единицы, и именно их перевод на другие языки представляет крайне сложную лингвистическую языковую проблему. Английский язык, как и русский, выработал языковые единицы для описания христианской темы (например, ветхозаветных сюжетов, истории пришествия Иисуса Христа), и они могут быть использованы в том числе при обращении к русскому православию [9].

Однако, разумеется, средств общехристианской лексики недостаточно для полноценного описания русского православия на английском языке, поскольку при описании православных реалий с помощью англоязычных лексических единиц важно учитывать и историческое развитие христианства. Очевидно, что английский язык прежде всего направлен на описание протестантизма и католичества. Для обозначения православных элементов английский язык приспособлен и в меньшей степени православия, учитывая, что первые упоминания о православии в Англии датируются лишь XVII веком.

Значительную часть религиозных идионимов составляют имена собственные, в том числе имена святых, то есть агиоантропонимы, понимаемым как «апеллятивно-антропонимический комплекс, служащий для номинации прославленных христианских святых». Структура агиоантропонима многокомпонентна и включает как обязательные, так и факультативные элементы [3]. Возможны следующие модели антропонимов:

1. двухкомпонентная модель: чин святости + имя: мученица Ирина, апостол Фома;

2. трехкомпонентная модель: чин святости+имя+дифференциатор, где в качестве дифференциатора, то есть лексической единицы, реализующей точную идентификацию святого (имена святых нередко совпадают) и дающих дополнительную информацию о святом, могут выступать:

- номинаторы (указание на занятие святого при жизни): священномученик Зотик пресвитер, преподобный Иосифр песноnисеч;

- дескрипторы (указание на личные качества и характеристика святого): святой Иоанн Златоуст, преподобный Арсений трудолюбивый;

- локализаторы (указание на месторождения, служения, подвига или погребения святого): Иоанн Кронштадтский, праведный Евдоким Каппадокиянин; 
- агномены, или прозвища (связь с особым событием в жизни святого): священномученик Игнатий Богоносеи, праведный Иосиф Обручник;

- когномены, или фамилии: святитель Игнатий (Брянчанинов); святой Николай Кочанов, Христа ради юродивый, Новгородский;

- этнонимы (указание на этнос): св. Иоанн Русский, св. Максим Перс;

3. четырехкомпонентная (и более) модель:

чин святости + имя + государственный титул или церковная должность + локализатор или чин святости + государственный титул или церковная должность + имя + локализатор, где государственный титул или церковная должность является факультативным элементом: святитель Макарий, митрополит Московский; св. благоверный князь Даниил Московский;

чин святости+имя+агномен+титул/должность +локализатор: святитель Григорий Двоеслов, папа Римский.

многокомпонентная модель с указанием на каноническое крестильное имя: благоверный и равноапостольный царь Борис, во Святом Крещении Михаил, креститель Болгарии; равноапостольный великий князь Владимир, во Святом Крещении Василий.

Обозначая одного и того же святого, агиоантропонимы могут образовывать различные номинации, которые варьируются от официальных наименований, отраженных в Минеях и святцах, до обиходных. Последние часто представляют собой сокращенные формулы агиоантропонимов. Несмотря на возможную редукцию агиоантропонима в обиходе и образование устойчивого словосочетания (например, Феофан Затворник, НиколаУгодник), все компоненты агиоантропонима как единого сложносоставного комплекса семантически значимы. В этом агиоантропоним отличается от антропонима, лишь факультативно сопровождающегося идентификаторами, которые могут стоять слева или справа относительно непосредственно ИС [3].

Обратимся к материалам сайта ОВЦС. Так, в русскоязычной версии имеется четыре варианта обозначения преподобного Варлаама Хутынского: одно полное наименование - преподобный Варлаам Хутынский - и три редуцированных: преподобный Варлаам, Варлаам Хутынский и святой Варлаам. В тексте переводных англоязычных статей наблюдается вариативность в передаче двух из четырех наименований.

Полное наименование преподобный Варлаам Хутынский является трехкомпонентным и включает такие элементы, как чин святости, имя и дифференциатор (локализатор). При переводе на английский язык модель принимает вид священный чин + имя + of + локали- затор. Заметным отличием от русской номинации является то, что локализатор представляет собой не образованное от топонима прилагательное, а сам топоним, который, как и в оригинале, стоит в постпозиции относительно имени. Для установления подчинительной связи между зависимым словом (локализатором) и главным словом (именем) применяется предлог of. Использование существительного вместо прилагательного объяснимо: локализатор как компонент ИС является информативным, и его семантику следует передавать в переводе. Англоязычный реципиент тогда распознает смысл онима, в данном случае - понимать, что святой жил в урочище под названием Хутынь. Возможно возражение, что русская номинация традиционно включает локализатор в форме прилагательного, поэтому получение значимой информации сопряжено с трансформацией от топонима в форме прилагательного до оригинального топонима. Мы полагаем, что носителю русского языка значительно легче провести данную трансформацию (Хутынский $\rightarrow$ Хутынь), чем иностранному читателю, и восприятие сведений русскоязычным реципиентом не затруднено.

\begin{tabular}{|l|l|}
\hline \multicolumn{1}{|c}{ Таблица 1} \\
\cline { 2 - 2 } преподобный Варлаам Хутынский & St. Varlaam of Khutyn \\
\cline { 2 - 2 } & the Venerable Barlaam of Khutyn \\
\cline { 2 - 2 } & the Venerably Barlaam of Khutyn \\
\cline { 2 - 2 } & St. Barlaam \\
\hline
\end{tabular}

В.В. Кабакчи считает преобразование русского локализатора (топонима в форме прилагательного) в вид of + локализатор, нежелательным, поскольку По его мнению, национальная самобытность сохраняется лишь при формальной транслитерации, которая обеспечивает максимальную близость к оригиналу [9]. В этом случае локализатор будет иметь вид Khutynsky. И это стремление к точности передачи формы слова Хутынский может привести к неполному восприятию смысла единицы, так как неподготовленный англоязычный реципиент может испытывать затруднение при установлении формы топонима, а, возможно, совсем не поймет, что дифференциатор является локализатором и несет смысловую нагрузку в виде обозначения места.

Модель священный чин + имя + of + локализатор также используется при передаче на английский язык имен русских святых в авторитетной двухтомной англоязычной энциклопедии The Encyclopedia of Eastern Orthodox Christianity, например: St. Tikhon of Zadonsk, St. Seraphim of Sarov, St. Sergius of Radonezh, St. Joseph of Volokolamsk. Эту же модель находим в известной работе английского богослова митрополита Диоклийского Каллиста TheOrthodoxChurch : St Nilus of Sora (Nil Sorsky); St. Joseph, Abbot of Volokalamsk и другие. Таким образом, мы считаем локализатор (of) Khutyn оптимальным вариантом, так как он выполняет те же функции, что и русскоязычный локализа- 
тор Хутынский: дифференцирующую и информативную.

В приведенных англоязычных вариантах имени преподобного Варлаама Хутынского чин святости преподобный передается либо как Venerable, либо как St. (сокращение от Saint). Компонент святой в составе русского онима святой Варлаам можно рассматривать как гипероним по отношению к различным чинам святости. Так, в Новом словаре русского языка Т. Ф. Ефремова [7] определяет святого как «того, кто провел жизнь в служении Богу и после смерти признан христианской церковью покровителем верующих». Близкое определение находим в Большом толковом словаре русского языка [2], где под святым понимается человек, проведший жизнь в служении Богу и церкви или пострадавший за христианскую веру и признанный церковью небесным покровителем верующих, а также способный творить чудеса. В «Англо-русском словаре в помощь христианскому переводчику» под ред. М. Макарова [11] saint (также Saint) в рассматриваемом нами значении переводится как святой (ж. святая). В качестве дополнительных вариантов перевода приводятся варианты канонизированный, причисленный к лику святых и мученник, и даются соответствия конкретно для православной традиции с пометой прав.: преподобный, блаженный, угодник, святитель, благоверный (при этом указывается, что ряд возможных вариантов перевода не ограничен этими соответствиями). Таким образом, хотя Saint (St.) шире по значению, чем преподобный, этот вариант использовать допустимо. Н.И. Колотовкин даже считает, что гипероним Saint следует использовать для передачи всех православных чинов святости, так как «на Западе никогда не существовало такой разветвлённой христианской терминологии, как на Востоке». Потеря смысла, по его мнению, в данном случае незначительна, а при необходимости можно прибегнуть к дополнительному комментарию [10, с.133].

Использование того или иного чина святости зависит от того, какой жизненный подвиг совершил святой. По нашему мнению, при генерализации конкретного чина до общего понятия Saint (St.) происходит существенная потеря информации о жизни святого. В связи с этим передача православного чина святости на английский язык является важной задачей для переводчика. Так как чины святости, используемые в русской православной традиции, без сомнений, обладают семантикой, мы считаем перевод (калькирование), а не транскрипцию этих единиц наиболее подходящим способом передачи. Также можно выделить ряд других преимуществ перевода как способа передачи чина святости в текстах, публикуемых на официальных сайтах РПЦ. Так, с целью сохранения единообразия все чины святости желательно передавать одним способом (либо переводом, либо транскрипцией), однако транскрибированная форма некоторых чинов святости (например, священномуче- ник и преподобномученик) представляется сложной для восприятия англоязычным реципиентом. Кроме того, в православном мире особое значение имеет стремление к сохранению единства Поместных Православных Церквей. Чины святости в православии являются общими для всех Поместных Церквей, которые ведут свою деятельность в разных странах с разными государственными языками (украинским, белорусским, сербским и др.). В условиях существования православия в разных языковых общностях логичным представляется разработка общепринятых вариантов передачи православной терминологии, в том числе чинов святости, на английском языке как языке-посреднике, который обеспечивает выход православия на широкую аудиторию. Поскольку тексты на англоязычных версиях официальных сайтов РПЦ ориентированы главным образом на широкую аудиторию в лице православных верующих, особое внимание должно уделяться соблюдению принципа доступности.

В переводных статьях ОВЦС наблюдается вариативность передачи и самого имени преподобного Варлаама Хутынского: Barlaam и Varlaam. Эти варианты отражают две тенденции в презентации православных агиоантропонимов на английском языке: соблюдение традиции передачи ИС, которая часто учитывает происхождение имени (Barlaam), и сохранение культурной (русской) самобытности (Varlaam). На наш взгляд, сначала нужно установить, входит ли агиоантропоним в словарный состав английского языка. Объективным признаком принадлежности языковой единицы к английскому языку можно считать ее включение в англоязычные толковые словари. В случае отсутствия единицы в толковом словаре следует обратить внимание на традицию передачи агиоантропонима в других авторитетных источниках, к которым мы относим в первую очередь англоязычные специальные словари и энциклопедии. Затем переводчик может обратиться к дополнительным англоязычным источникам, которые показывают вариант ИС, функционирующий в современном языке (например, православным англоязычным сайтам). Если закрепленный в словарях и энциклопедиях и использующийся в других источниках вариант ошибочен или неточен, переводчик может обоснованно предложить свой вариант перевода.

Роль устоявшейся традиции передачи того или иного агиоантропонима (как и любого другого агионима) нельзя преуменьшать. Если в иностранном языке долгое время функционирует определенный вариант передачи ИС, который носители напрямую и безошибочно связывают с определенным референтом, введение новой номинации (пусть и с благими намерениями, например, в целях отражения культурной специфики), существенно отличающейся от традиционной, может вызвать путаницу. Так, Д.И. Ермолович говорит о существовании двух подходов к передаче имен религиозных деятелей (в том числе святых): переводческой транскрипции (Aleksy, losif, Kirill) и 
традиционных соответствий с использованием транспозиции (Alexius, Joseph, Cyril). Мы поддерживаем рекомендацию Д.И. Ермоловича транспонировать русскоязычные агионимы библейского, греческого или латинского происхождения (Федор - Theodore) и транскрибировать имена чисто русского происхождения, которые не имеют библейских, греческих или латинских прототипов (митрополит Владимир - Metropolitan Vladimir) [6]. Однако если речь идет о людях, живущих в современную эпоху, то нет необходимости «англизировать» русские имена, используя этимологически родственные [5].

Таким образом, в качестве соответствия русской ономастической единицы преподобный Варлаам Хутынский предлагаем вариант Venerable Barlaam of Khutyn. В рамках текста на русском языке русскоязыч- ные наименования (как полные, так и редуцированные) рассматриваются нами как равнозначные и взаимозаменяемые. Однако важно понимать, что, будучи взятыми по отдельности, данные ИС сообщают разный объем информации (например, в случае отсутствия локализатора сведения о месте недоступны, а при использовании гиперонима святой чин святого не конкретизируется). При переводе на английский язык главной задачей переводчика является полноценная передача всего ономастического комплекса, который складывается из непосредственно имени собственно и других компонентов, в частности, локализатора и чина святости. Последний, на наш взгляд, следует переводить с помощью уже функционирующих в английском языке (но еще не принятых повсеместно) соответствий для точного отражения смысла.

\section{ЛИТЕРАТУРА}

1. Азаров А.А. Русско-английский словарь религиозной лексики https://azbyka.ru/otechnik/Spravochniki/russko-anglijskij-slovar-religioznoj-leksiki/11102 (дата обращения: 01.09.2021).

2. Большой толковый словарь русского языка / Сост. и гл. ред. С. А. Кузнецов. - Санкт-Петербург: Норинт, 2000. С. 1164.

3. Бугаева И.В. Язык православной сферы: современное состояние, тенденции развития: диссертация доктора филологических наук / И.В. Бугаева. - МоСКВа, 2010. С. 239-246.

4. Бугаева И.В. Агионимы в ономастическом пространстве русского языка / И.В. Бугаева. - Текст: электронный // Образовательный портал «Слово»: сайт. URL: https://www.portal-slovo.ru/philology/45446.php\#_edn1 (дата обращения: 01.09.2021).

5. Ермолович Д.И. Имена собственные на стыке языков и культур / Д.И. Ермолович. - Москва: Р.Валент, 2001. С.80.

6. Ермолович Д.И. Русско-английский перевод / Ермолович Д.И. - 2-е изд., испр. и доп. - Москва: Аудитория, 2015. С. 96-97.

7. Ефремова Т.Ф. Новый словарь русского языка /Текст: электронный // сайт. - URL: https://classes.ru/all-russian/russian-dictionary-Efremova-term-97714.htm (дата обращения: 01.09.2021).

8. Историческая справка. - Текст: электронный // Отдел внешних церковных связей Московского Патриархата: сайт. - URL: https://mospat.ru/ru/ department/history/ (дата обращения: 01.09.2021).

9. Кабакчи В.В. Практика английского языка межкультурного общения: Religion, Christianity, RussianOrthodoxy (Pravoslavie) / В. В. Кабакчи. - СПб: ИВЭСЭП, Знание, 2001. С. 7-8, 165.

10. Колотовкин Н.И. Презентация православной лексики в общих и специальных словарях: на материале английского и русского языков: диссертация... . кандидата филологических наук. - Москва, 2013. С.133. Лики святости. - Текст: электронный // Портал «Азбука веры»: caйт. - URL: (https://azbyka.ru/ days/p-tip-svjatosti (дата обращения: 01.09.2021).

11. Макаров М. Англо-русский словарь в помощь христианскому переводчику/Текст: электронный // сайт. - URL: http://greeklatin.narod.ru/anglo/anglo.htm (дата обращения: 01.09.2021).

12. Тимофеев К.А. Религиозная лексика русского языка как выражение христианского мировоззрения: монография / К.А. Тимофеев. - Новосибирск, 2001. С. 3.

(c) Пономарева Светлана Николаевна (spatz@mail.ru), Шаврина Ульяна Андреевна (ulyana.shavrina@gmail.com).

Журнал «Современная наука: актуальные проблемы теории и практики» 